Editorial

\title{
Is Minimal CAD a Prognostic Marker in Dilated Cardiomyopathy?
}

\author{
Lalita Nemani ${ }^{1}$ \\ 1 Department of Cardiology, Nizam's Institute of Medical Science, \\ Hyderabad, Telangana, India \\ Ind J Car Dis Wom 2021;6:228-229.
}

Idiopathic dilated cardiomyopathy (IDCM) is defined by the presence of left ventricular dysfunction and angiographically normal coronaries according to the standard definitions and criteria. There should be no significant coronary artery disease (CAD) (luminal narrowing should not be $\geq 50 \%$ angiographically) and left ventricular ejection fraction should be reduced $(<45 \%)$ with no specific heart muscle disease on endomyocardial biopsy. ${ }^{1,2}$ This includes patients with normal coronaries and patient without significant CAD also referred as minimal CAD.

Angiographically minimal CAD has been frequently described (36-68\%) in patients diagnosed with IDCM. ${ }^{3}$ In these cases, the coronary lesion is assumed to be unrelated to the left ventricular dysfunction. However, follow-up of many such cases has identified obstructive coronary atherosclerotic lesions in end-stage hearts excised at transplant, paving way for probable initial misdiagnosis. This doubt is further strengthened by a recent gadolinium-enhanced cardiovascular magnetic resonance study, ${ }^{4}$ where $13 \%$ patients diagnosed with IDCM on basis of coronary angiography showed myocardial enhancement indistinguishable to patients with CAD.

However, the above state of misdiagnosis of ischemia is not always true. A recent study ${ }^{5}$ showed that $27 \%$ hearts diagnosed as IDCM with angiographically normal coronaries at the time of diagnosis had significant coronary lesions when excised at the time of transplant. Though similar findings have also been reported in previous pathological studies, this study differs in that DCM was rightly defined as idiopathic after excluding ischemia by all measures at the initial diagnosis. This study supports the fact that finding of CAD at later stage was not a misdiagnosis at entry level. The angiopathological mismatch in the study has been attributed to multiple factors such as underestimation of coronary atherosclerosis by coronary angiogra- phy, overestimation of luminal narrowing by pathological evaluation, coronary artery dilation that accompanies left ventricular dilation, and possible progression of atherosclerosis. Conclusion of the study was that CAD was not a missed entity but a comorbidity that was either absent or insignificant at the time of initial diagnosis. The risk factors for CAD remain the same be it DCM patients or non-DCM patients, as rightly pointed by the present author and many previous studies.

Lutz Frankenstein et al had first showed that associated CAD was frequent in DCM patients, but it did not predict mortality or hospitalization secondary to cardiac decompensation. ${ }^{6}$ Recent evidence ${ }^{7,8}$ shows heart failure (HF) with reduced ejection fraction and concomitant minimal CAD fared worse than not associated CAD. According to Braga et $\mathrm{al}^{9}{ }^{9}$ minimal CAD in HF patients was independently associated with an increased hazard of the primary composite outcome (cardiovascular [CV] death, nonfatal myocardial infarction, nonfatal stroke, or HF hospitalization) and death due to any cause. In their study, cohort of 12,814 patients with heart failure with reduced ejection fraction (HFrEF) (EF $<35 \%$ ), the relative hazard for nonobstructive CAD was 1.17 $(p=0.01)$ in comparison to normal coronary arteries. There were no significant differences between the two groups in the hazard of experiencing an acute myocardial infarction (AMI), hospitalization for HF, or stroke. This study supports the role of minimal CAD in diastolic dysfunction attributed to myocardial fibrosis, ventricular stiffness, and coronary microvascular dysfunction. ${ }^{10,11}$ In the nonobstructive CAD group, cumulative incidence of non-CV death was higher (11\%) than CV death (8.0\%). The increased risk of both allcause and $\mathrm{CV}$ mortality but not AMI suggests the role for associated comorbidity. The prognostic risk of nonobstructive CAD among patients with HFrEF was also established by Maddox et al. ${ }^{8}$
Address for correspondence Lalita Nemana, MD, DM, FESC, Department of Cardiology, Nizam's Institute of Medical Science, Hyderabad, Telangana 500082, India

(e-mail: drlalita775@gmail.com).
DOI https://doi.org/ $10.1055 / \mathrm{s}-0041-1740356$. ISSN 2455-7854. (c) 2022. Women in Cardiology and Related Sciences. All rights reserved.

This is an open access article published by Thieme under the terms of the Creative Commons Attribution-NonDerivative-NonCommercial-License, permitting copying and reproduction so long as the original work is given appropriate credit. Contents may not be used for commercial purposes, or adapted, remixed, transformed or built upon. (https://creativecommons.org/ licenses/by-nc-nd/4.0/)

Thieme Medical and Scientific Publishers Pvt. Ltd., A-12, 2nd Floor, Sector 2, Noida-201301 UP, India 
The present article titled "Is Minimal Coronary Artery Disease a Prognostic Indicator in Dilated Cardiomyopathy" in this issue of the journal has shown significant association of minimal CAD with cardiac decompensation in DCM patients in the form of $\mathrm{HF}$ requiring hospitalization, though there is no association with mortality. The possible explanation of this comorbidities contributing to diastolic abnormalities by the authors seems plausible. The absence of effect on mortality attributed to optimal medical therapy emphasizes the need to implement optimal guideline-direct medical therapy in these patients.

The available research emphasizes the need to subclassify IDCM patients by comorbidities to better understand the factors influencing evolution of disease. Clinical risk assessment combined with cardiac magnetic resonance imaging and pathological findings would provide definitive answer to the role of minimal CAD and/or related risk factors in influencing the outcome in IDCM. On the basis of the available data, we can conclude that in clinical practice, every attempt should be made for the assessment of CAD in patients with IDCM by risk factor evaluation, genetic profiling, and cardiac imaging (computed tomographic imaging $^{12,13}$ and quantitative positron emission tomography myocardial perfusion studies) as it adversely affects the outcome in these patients.

\section{Conflict of Interest}

None declared.

\section{References}

1 Felker GM, Shaw LK, O'Connor CM. A standardized definition of ischemic cardiomyopathy for use in clinical research. J Am Coll Cardiol 2002;39(02):210-218

2 Mestroni L, Maisch B, McKenna WJ, et al; Collaborative Research Group of the European Human and Capital Mobility Project on Familial Dilated Cardiomyopathy. Guidelines for the study of familial dilated cardiomyopathies. Eur Heart J 1999;20(02): 93-102
3 Angelini A, Boffa GM, Livi U, Barchitta A, Casarotto D, Thiene G. Discordance between pre and post cardiac transplant diagnosis: implications for pre- and postoperative decision making. Cardiovasc Pathol 1999;8(01):17-23

4 McCrohon JA, Moon JCC, Prasad SK, et al. Differentiation of heart failure related to dilated cardiomyopathy and coronary artery disease using gadolinium-enhanced cardiovascular magnetic resonance. Circulation 2003;108(01):54-59

5 Repetto A, Dal Bello B, Pasotti M, et al. Coronary atherosclerosis in end-stage idiopathic dilated cardiomyopathy: an innocent bystander? Eur Heart J 2005;26(15):1519-1527

6 Lutz F, Henrik H, et al. Clinical characteristics, morbidity, and prognostic value of concomitant coronary artery disease in idiopathic dilated cardiomyopathy. Clin Res Cardiol 2013. Doi: 10.1007/s00392-013-0589-7

7 Schulman-Marcus J, Hartaigh BO, Gransar H, et al. Sex-specific associations between coronary artery plaque extent and risk of major adverse cardiovascular events: the CONFIRM long-term registry. JACC Cardiovasc Imaging 2016;9(04):364-372

8 Maddox TM, Stanislawski MA, Grunwald GK, et al. Nonobstructive coronary artery disease and risk of myocardial infarction. JAMA 2014;312(17):1754-1763

9 Braga JR, Austin PC, Ross HJ, Tu JV, Lee DS. Importance of nonobstructive coronary artery disease in the prognosis of patients with heart failure. JACC Heart Fail 2019;7(06):493-501

10 Elgendy IY, Pepine CJ. Heart failure with preserved ejection fraction: is ischemia due to coronary microvascular dysfunction a mechanistic factor? Am J Med 2019;132(06):692-697; [E-pub ahead of print]

11 Taqueti VR, Solomon SD, Shah AM, et al. Coronary microvascular dysfunction and future risk of heart failure with preserved ejection fraction. Eur Heart J 2018;39(10):840-849

12 Bittencourt MS, Hulten E, Ghoshhajra B, et al. Prognostic value of nonobstructive and obstructive coronary artery disease detected by coronary computed tomography angiography to identify cardiovascular events. Circ Cardiovasc Imaging 2014;7(02):282-291

13 Chow BJ, Small G, Yam Y, et al; CONFIRM Investigators. Prognostic and therapeutic implications of statin and aspirin therapy in individuals with nonobstructive coronary artery disease: results from the CONFIRM (COronary CT Angiography EvaluatioN For Clinical Outcomes: An InteRnational Multicenter registry) registry. Arterioscler Thromb Vasc Biol 2015;35(04):981-989 